\title{
PROBLEMATIKA PENGAWASAN DEWAN PENGAWAS SYARIAH PADA BMT ALMAUN BERKAH MADANI DAN BMT MANDIRI UKHUWAH PERSADA ${ }^{1}$
}

\author{
Fathin Su'aidi \\ Departemen Ekonomi Syariah-Fakultas Ekonomi dan Bisnis-Universitas Airlangga \\ Email: fathinsuaidi@gmail.com \\ Irham Zaki \\ Departemen Ekonomi Syariah-Fakultas Ekonomi dan Bisnis-Universitas Airlangga \\ Email: irhamzaki0712@gmail.com
}

\begin{abstract}
:
Sharia Board is an commite in sharia financial institution and assigned overseeing the implementation of the decisions of the National Sharia Board (DSN) in Islamic financial institutions. Sharia Board functions to supervise sharia compliance in sharia financial institutions including the Baitul Maal Waat Tamwil (BMT). BMT is a sharia micro finance institution that combines the concept of maal and tamwil. This study aims to determine the problems faced by the Sharia Board in conducting supervision in BMT. The point that is necessary reviewed in this supervisory practice are based on Decree MUI DSN No. 3 of 2000 concerning instructions for implementing the determination of members of the sharia board in sharia financial institutions. This study use qualitative methods with descriptive case study strategy. From the results of the research occur several problems were encountered by the Sharia Board including: lack of the professionalism of Sharia Board, lack of commitment, lack of independence, and challange to mobilize all elemnts os sharia financial institution to comply with sharia law. The sloution of the problematic is by upgrade an increase faith and taqwa ang commitment to enforce sharia especially as the Sharia Board. always implementing the principles of Good Corporate Governance, and the governmemt making strong and clear rules of sharia supervisions.
\end{abstract}

Keywords: Problematic, Sharia Board, Baitul Maal Wat Tamwil.

\section{PENDAHULUAN}

Lembaga keuangan syariah mengalami perkembangan yang pesat di Indonesia. Perkembangan itu ditandai dengan berdirinya bank syariah pertama di Indonesia yaitu Bank Muamalah Indonesia pada tahun 1992. Setelah itu diikuti dengan Undang-Undang No 7 Tahun 1992 tentang perbankan yang mengakomodasi perbankan syariah.

Lembaga keuangan syariah nonbank memiliki potensi untuk terus tumbuh dan memiliki kemanfaatan khususnya untuk masyarakat yang tidak bankable, yaitu lembaga keuangan mikro syariah. Lembaga keuangan mikro syariah ditujukan untuk mendorong meratanya pemberdayaan ekonomi di masyarakat menengah kebawah yang memiliki penghasilan rendah dan usaha mikro. Lembaga keuangan mikro syariah yang ada saat ini salah satunya yaitu Baitul Maal Wat Tamwil.

$$
\text { Menurut Masyitoh (2014) Baitul }
$$

Maal Wat Tamwil merupakan lembaga kevangan dengan dengan menggabungkan konsep maal dan tamwil dalam satu kegiatan lembaga.

\footnotetext{
${ }^{1}$ Jurnal ini merupakan bagian dari skripsi yang ditulis oleh Fathin Su'aidi, NIM: 041511433033 , yang diuji pada 19 Juli 2019.
} 
Su'aidi, et al/Jurnal Ekonomi Syariah Teori dan Terapan Vol. 6 No. 11 November 2019: 2361-2368; PROBLEMATIKA PENGAWASAN DEWAN PENGAWAS SYARIAH PADA BMT ALMAUN BERKAH MADANI DAN BMT MANDIRI UKHUWAH PERSADA

Menurut Masyitoh (2014) Baitul Maal Wat Tamwil merupakan lembaga keuangan dengan dengan menggabungkan konsep maal dan tamwil dalam satu kegiatan lembaga. Kehadiran BMT menjadi pilihan untuk masyarakat yang gelisah dengan kegiatan ekonomi dengan prinsip riba, sekaligus sebagai supporting funding untuk mengembangkan kegiatan pemberdayaan usaha kecil dan menengah. Kehadiran Baitul Maal Wat Tamwil dirasakan telah membawa manfaat finansial bagi masyarakat, terutama masyarakat kecil yang tidak bankable dan setuju dengan penolakan riba.

Majelis Ulama Indonesia (MUI) membentuk Dewan Syariah Nasional (DSN) sebagai langkah untuk mengkoordinasikan ulama dalam menanggapi isu-isu yang berhubungan dengan ekonomi atau keuangan syariah untuk mendorong penerapan ajaran islam dalam ekonomi (Nuha, 2018). Dalam upaya menjaga kepatuhan syariah Islam Dewan Pengawas Syariah (DPS) wajib dimiliki oleh lembaga keuangan syariah sesuai dengan surat keputusan DSN MUI No. 3 tahun 2000.

Menurut Fauzan dalam Kusuma (2017) ada beberapa faktor kendala yang dialami oleh DPS dalam melakukan pengawasan seperti adanya beberapa aanggota DPS yang kurang menguasai figh muamalah terapan dan ilmu perbankan dan juga masih banyak anggota DPS yang belum bisa membedakan antara bunga dan margin murabahah.

Hasil penelitian Eko Kuswanto (2018) kendala yang dialami DPS yaitu terkait profesionalitas yang dibuktikan dengan sertifikat dan kesibukan DPS karena memiliki kesibukan lain yang mengganggu fokus dalam pengawasan.

Pada penelitian ini penulis mengambil studi kasus pada dua Baitul Maal Wat Tamwil yaitu BMT Almaun Berkah Madani (Almaun) yan terbilang masih baru dan BMT Mandiri Unkuwah Persada (MUDA) yang sudah cukup mapan di Kota Surabaya untuk mengetahui problematika DPS yang di hadapi. Setelah itu di tarik inti permasalahan dan menemukan solusi atas problematika.

\section{LANDASAN TEORI DAN PENGEMBANGAN HIPOTESIS}

Baitul Maal Wat Tamwil merupakan lembaga keuangan dengan konsep syariah yang lahir dengan menggabungkan konsep maal dan tamwil dalam satu kegiatan lembaga. Konsep maal lahir dalam hal menghimpun dan menyalurkan dana untuk zakat, infaq, dan shodaqoh (ZIS) secara produktif. Sedangkan konsep tamwil untuk kegiatan bisnis produktif yang murni untuk mendapatkan keuantungan atau laba dengan target masyarakat menengah ke bawah atau mikro. BMT dapat mengakomodir kebutuhan yang terjadi di masyarakat menengah kebawah yang memiliki kegelisahan dalam kegitan 
Su'aidi, et al/Jurnal Ekonomi Syariah Teori dan Terapan Vol. 6 No. 11 November 2019: 2361-2368; PROBLEMATIKA PENGAWASAN DEWAN PENGAWAS SYARIAH PADA BMT ALMAUN BERKAH MADANI DAN BMT MANDIRI UKHUWAH PERSADA

ekonomi konvensional yang menggunakan prinsip riba, sekaligus untuk mendukung pengembangan kegiatan ekonomi usaha kecil dan menengah. Dapat ditarik kesimpulan dari pengertian tersebut bahwa BMT merupakan lembaga yang berfokus pada dua aspek yaitu sosial dan bisnis yang berfokus pada masyarakat mikro. Artinya pengawasan adalah faktor penting untuk memastikan kesesuaian target dan hasil dari kinerja yang sudah dilakukan.

BMT di Indonesia kebanyakan berbadan usaha koperasi syariah. BMT Almaun dan BMT MUDA juga BMT yang berbadan hukum Koperasi Syariah. Pengawasan dalam BMT dilakukan dalam dua aspek yaitu aspek manajemen koperasi oleh dewan pengawas dan pengawasan kepatuhan syariah oleh Dewan Pengawas Syariah. Keduanya memiliki peran penting yaitu untuk mengawasi BMT agar tetap bisa berkembang dan juga mematuhi aturan syariah yang telah diatur oleh DSN MUI.

Pengawasan merupakan bagian dari konsep manajemen yang berfungsi sebagai kontrol dan perbaikan dari sebuah pelaksanaan kerja. Pengawasan ditujukan untuk menghindari adanya kemungkinan penyelewengan atau penyimpangan atas tujuan yang akan dicapai. Pengawasan Syariah dilakukan oleh Dewan Pengawas Syariah.

Dewan Pengawas Syariah BMT diatur oleh peraturan Menteri Koperasi dan UKM RI No.35.2/PER/M.KUKM /X/2007 tentang Pedoman Standar Opersional Manajemen KJKS dan UJKS Koperasi. Dewan pengawas syariah pada KJKS dan UJKS Koperasi adalah dewan yang dipilih oleh koperasi yang bersangkutan berdasarkan keputusan rapat anggota dan beranggotakan alim ulama yang ahli dalam syariah yang menjalankan fungsi dan tugas sebagai dewan pengawas syariah pada koperasi yang bersangkutan dan wewenang memberikan tanggapan atau penafsiran terhadap fatwa yang dikeluarkan Dewan Syariah Nasional.

Problematika adalah kendala atau permasalahan yang masih belum dapat dipecahkan sehingga untuk mencapai tujuan menjadi terhambat dan tidak maksimal. Dalam konteks penelitian ini problematika yang dimaksud adalah probematika atau masalah yang dihadapi Dewan Pengawas Syariah dalam melakukan pengawasan di BMT. Acuan utama yang digunakan untuk melakukan pengawasan adalah keputusan DSN MUI No. 3 Tahun 2000 tentang Petunjuk Pelaksanaan Anggota Dewan Pengawas Syariah Pada Lembaga Kevangan Syariah.

DPS bertugas untuk mengawasi segala aktivitas lembaga keuangan agar selalu sesuai dengan prinsip-prinsip syariah. DPS bertanggung jawab atas produk dan jasa yang ditawarkan kepada masyarakat agar sesuai dengan prinsip syariah, selain itu investasi atau proyek yang ditangani juga harus sesuai dengan syariah, dan tentu pengelolaan 
Su'aidi, et al/Jurnal Ekonomi Syariah Teori dan Terapan Vol. 6 No. 11 November 2019: 2361-2368; PROBLEMATIKA PENGAWASAN DEWAN PENGAWAS SYARIAH PADA BMT ALMAUN BERKAH MADANI DAN BMT MANDIRI UKHUWAH PERSADA

manajemen lembaganya harus sesuai syariah.

Secara umum tugas dan fungsi DPS adalah melakukan pengawasan dan pengarahan atas aktivitas lembaga kevangan syariah agar sesuai dengan aturan dan prinsip yang diterapkan dalam fatwa-fatwa DSN, serta melaporkan hasil pengawasan kepada DSN. Peran yang sangat penting dimiliki oleh dewan pengawas syariah karena berperan menjamin kesesuaian syariah seluruh kegiatan pengelolaan maupun produk dan jasa yang dikeluarkan oleh lembaga kevangan syariah.

Merujuk pada kualifikasi, tugas dan kewajiban DPS, maka selayaknya DPS mampu mengontrol ketat perilaku lembaga keuangan syariah (LKS). DPS dituntut untuk melaksanakan tugas dan kewajibannya dengan benar agar LKS sesuai dengan prinsip-prinsip syariah.

Hal diatas bertolak belakang dengan syarat seseorang yang akan menjadi DPS yaitu memiliki akhlaqul karimah. DPS juga harus memiliki kompetensi dalam bidang muamalah dan keuangan secara umum serta komitmen untuk mengembangkan kevangan berdasarkan syariah. berdasarkan kualifikasi tersebut harus dibuktikan dengan sertifikat sebagai DPS yang dikelvarkan oleh DSN.

Sudah seharunya DPS sebagai orang yang memiliki kualifikasi dalam melakukan pengawasan kepatuhan syariah memiliki independensi dengan menilai secara objektif. Dalam melakukan diperlukan objektivitas dan independensi agar tidak terpengaruh oleh pihak lain. Lin Emy prastiwi (2017) dalam penelitiannya yang berjudul "Pengaruh Independensi Dewan Pengawas Syariah Dalam Mewujudkan Good Corporate Governance untuk meningkatkan kinerja BMT" menyebutkan bahwa dari uji statistik yang dilakukan independensi DPS berpengaruh signifikan terhadap kinerja BMT di kabupaten Sukoharjo dan Karanganyar.

\section{METODE PENELITIAN}

Metode penelitian metode Penelitian ini menggunakan metode kualitatif yang menurut Nazir (2003) pendekatan kualitatif adalah pendekatan dengan menggunakan data yang berupa kalimat tertulis atau lisan, peristiwaperistiwa, pengetahuan, atau studi yang bersifat deskriptif. Penelitian kualitatif dilakukan pada kondisi alamiah dan bersifat penemuan.

Pendekatan kualitatif yang digunakan adalah dengan metode studi kasus. Penelitian studi kasus adalah studi yang mengeksplorasi suatu masalah dengan batasan terperinci, memiliki pengambilan data yang mendalam, dan menyertakan berbagai sumber informasi.. (Moelong, 2004).

Penelitian kualitatif ini menggunakan teknik triangulasi untuk menguji kebsahan datanya. Data-data yang diperoleh dari berbagai sumber diperlukan pengecekan lebih lanjut untuk 
Su'aidi, et al/Jurnal Ekonomi Syariah Teori dan Terapan Vol. 6 No. 11 November 2019: 2361-2368; PROBLEMATIKA PENGAWASAN DEWAN PENGAWAS SYARIAH PADA BMT ALMAUN BERKAH MADANI DAN BMT MANDIRI UKHUWAH PERSADA

memenuhi syarat objektivitas dan kredibilitas, yaitu melalui proses triangulasi sumber. Menurut Yin (2003:111), teknik penjodohan pola merupakan prosedur analisis yang relevan untuk penelitian ini, yakni menjodohkan pola pengawasan yang dilakukan oleh DPS BMT Almaun Berkah Madani dan BMT Mandiri Uhkuwah Persada (MUDA) dengan keputusan DSN MUI No. 3 Tahun 2000.

\section{HASIL DAN PEMBAHASAN}

Dalam melakukan pengawasan Dewan Pengawas Syariah harus mematuhi fatwa-fatwa DSN MUI sebagai pembuat kebijakan tentang syariah di Indonesia. Sebagai lembaga yang berbadan hukum koperasi, BMT belum mendapat perhatian khusus dari pihak Kementrian Koperasi dan UMKM. Selain itu juga dalam pengawasan syariah, BMT belum yang mengikat secara kuat. Pengawasan mengacu kepada fatwa DSN MUI namun pada pelaksanannya tidak ada aturan sehingga tidak adanya controlling yang dilakukan.

Kualifikasi, tugas dan fungsi, serta kewajiban DPS dijelaskan pada keputusan DSN MUI No 3 tahun 200. Diantaranya DPS harus memiliki sertifikat DPS, Mengawasi kegiatan lembaga keuangan syariah agar sesuai dengan prinsip syariah yang telah difatwakan oleh DSN, memberi nasehat dan saran kepada direksi atau manajer mengenai aspek syariah, sebagai mediator antara lembaga keuangan dan DSN jika membutuhkan fatwa baru, mengikuti fatwa yang telah ditentukan
DPS dan juga membuat laporan kepada DSN minimal dua kali dalam setahun.

Dari hasil Penelitian beberapa problematika yang dihadapi DPS di BMT Almaun, antara lain: Kurangnya inisiatif dari DPS dalam melakukan pengawasan, Kurangnya inisiatif DPS sehingga terjadi komunikasi yang kurang efektif dan efisien antara DPS dan Manajer Keaktifan DPS sebagai pengawas yang dinilai kurang karena masih belum fokus dalam pengawasan syariah BMT, Hasil laporan Pengawasan DPS yang tidak ada tindak lanjut dari DSN.

Problematika yang dihadapi DPS pada BMT MUDA, diantaranya : DPS memiliki kesibukan lain selain menjadi pengawas syariah sehingga tidak fokus dalam mengawasi.Tantangan yang berat untuk mengajak seluruh elemen BMT dalam mematuhi syariah terutama mengajak anggota, Tuntutan untuk selalu istiqomah dalam mematuhi aturan syariah harus dilakukan bersama - sama dan saling mengawasi, Kesulitan mencari orang sebagai DPS yang mau berkomitmen kuat dalam menjaga kepatuhan syariah.

Solusi merupakan penyelesaian atau pemecahan maasalah dari problem yang terjadi. Solusi yang baik adalah solusi yang bisa menyelesaikan masalah dari sebuah problematika. Problematika atau masalah yang ada dapat dikelompokkan menjadi beberapa kelompok karena memiliki sumber masalah yang sama. Menyelesaikan masalah dari sumber 
Su'aidi, et al/Jurnal Ekonomi Syariah Teori dan Terapan Vol. 6 No. 11 November 2019: 2361-2368; PROBLEMATIKA PENGAWASAN DEWAN PENGAWAS SYARIAH PADA BMT ALMAUN BERKAH MADANI DAN BMT MANDIRI UKHUWAH PERSADA

masalah merupakan cara yang efektif dan efisien, sumber masalah yang terjadi berasal dari : individu Dewan Pengawas Syariah, Lembaga keuangan syariah, dan Dewan Syariah Nasional.

Solusi yang baik adalah solusi yang bisa menyelesaikan masalah dari sebuah problematika. Problematika atau masalah yang ada dapat dikelompokkan menjadi beberapa kelompok karena memiliki sumber masalah yang sama. Menyelesaikan masalah dari sumber masalah merupakan cara yang efektif dan efisien, sumber masalah yang terjadi berasal dari : individu Dewan Pengawas Syariah, Lembaga keuangan syariah, dan Dewan Syariah Nasional.

$$
\text { Menjadi seorang Dewan }
$$

Pengawas Syariah merupakan suatu hal yang tidak mudah karena harus memenuhi kualifikasi yang sudah ditentukan oleh DSN MUI. DPS harus memiliki akhlaqul karimah, berkomitmen dalam mengembangkan keuangan syariah, memahami keilmuan figh muamalah dan lembaga keuangan secara umum. Kualifikasi tersebut dapat dibuktikan dengan sertifikat DPS yang diberikan setelah mengikuti dan lulus dalam sertifikasi oleh DSN.

Iman dan Taqwa adalah sebuah dasar yang harus dimiliki dan dipraktikkan dengan sungguh - sungguh oleh umat islam. Setidaknya harus berusaha untuk melaksanakan perintah dan menjauhi larangan - larangan Allah. Satu sifat yang wajib dimiliki oleh seseorang adalah ihsan.
Seorang yang ishan menganggap bahwa dirinya selalu diawasi oleh Allah sehingga bisa menghindari perbuatan yang kurang baik.

Semua elemen dalam lembaga kevangan syariah memiliki peran yang penting untuk menjadikan kemajuan lembaga keuangan. Mulai atas hingga bawah harus bersinergi mewujudkan Good Corporate Governance (GCG). Good Corporate Governance merupakan wujud keseriusan lembaga keuangan syariah untuk membangunkepercayaan masyarakat agar bisa berkembang dengan baik dan sehat. Good Corporate Governance memiliki lima prinsip utama yaitu: keterbukaan (transparency), akuntabilitas (accountability), tanggung jawab (responsibility), independensi (independency), serta kewajaran (fairness). (Komite Nasional Kebijakan Governance : 2004)

\section{Pelaksanakan Good Corporate} Governance berpengaruh terhadap kinerja lembaga keuangan syariah. Hal tersebut ditunjukkan dari uji statistik yang dilakukan oleh lin Emy Prastiwi (2017) dalam penelitiannya yang berjudul "Pengaruh Independensi Dewan Pengawas Syariah Dalam Mewujudkan Good Corporate Governance Untuk Meningkatkan Kinerja BMT".

Faktor yang sangat penting dalam menyelesaikan problematika Dewan Pengawas Syariah adalah pembuat kebijakan. Dalam hal ini Dewan Syariah Nasional merupakan lembaga yang harus 
Su'aidi, et al/Jurnal Ekonomi Syariah Teori dan Terapan Vol. 6 No. 11 November 2019: 2361-2368; PROBLEMATIKA PENGAWASAN DEWAN PENGAWAS SYARIAH PADA BMT ALMAUN BERKAH MADANI DAN BMT MANDIRI UKHUWAH PERSADA

memiliki sistem pengawasan syariah secara rinci untuk seluruh lembaga kevangan syariah sesuai dengan kebutuhannya. Aturan - aturan perlu ditegakkan dan diawasi secara formal dan legal. Dimulai dari sertifikasi DPS yang dilakukan dengan maksimal untuk mendapatkan DPS yang berkualitas. Setelah itu membuat standar operasional prosedur atau pedoman pengawasan agar DPS memiliki satu acuan yang sama dalam melakukan proses pengawasan. Mewajibkan pelaporan tahunan dari DPS setiap lembaga keuangan dengan tujuan melakukan evaluasi terhadap konsep dan aplikasi dari fatwa-fatwa DSN.

Hicem Hamza (2013) menjelaskan Independensi dan konsistensi Dewan Pengawas Syariah adalah prinsip utama yang bisa membuat efisien struktur lembaga keuangan. Hal tersebut dapat dicapai dengan adanya aturan legal yang jelas mengatur pengawasan syariah secara rinci mulai dari sertifikasi DPS, pedoman pengawasan DPS, dan laporan kepatuhan syariah secara berkala.

\section{SIMPULAN}

Dari hasil penelitian yang dilakukan pada penelitian ini, problematika yang dihadapi oleh DPS di kedua BMT memiliki bebrapa kesamaan. Problematika pada penelitian pada BMT Almaun dan BMT MUDA antara lain : pertama, DPS memiliki kesibukan lain selain menjadi pengawas syariah sehingga tidak fokus dalam mengawasi. Hal itu membuat profesionalitas DPS kurang. Kedua, tantangan yang berat untuk mengajak seluruh elemen BMT dalam mematuhi syariah terutama mengajak anggota. Sehingga memerlukan komitmen yang kuat untuk berjuang menegakkan syariah pada BMT. Ketiga, Tuntutan untuk selalu istiqomah dalam mematuhi aturan syariah harus dilakukan bersama - sama dan saling mengawasi. Keempat, Kurangnya inisiatif dari DPS dalam melakukan pengawasan syariah. Hal ini menyebabkan pengwasan kurang efisien. Kelima, Komunikasi antar elemen pada BMT yang harus dijaga agar tidak ada suatu perbedaan pandangan, keenam, Hasil laporan Pengawasan DPS yang tidak ada tindak lanjut dari DSN. Tidak adanya aturan yang mengikat secara hukum sehingga tidak ada laporan yang disampaikan. Ketujuh, Indepensi DPS harus terjaga agar mengawasi kepatuhan syariah secara objektif untuk kebaikan bersama. Tujuannya untuk meningkatkan kepercayaan masyarakat terhadap kredibilitas lembaga keuangan syariah. Solusi untuk problematika pengawasan DPS pada lembaga kevangan syariah dapat dilakukan dengan mengoptimalkan kualitas diri dari DPS dengan memperkuat iman dan taqwa sebagai hamba Allah, setiap lembaga keuangan syariah harus mematuhi prinsip Good Corporate Governance untuk meningkatkan kinerja, dan DSN bekerjasama dengan pembuat kebijakan lain dalam hal keuangan syariah membuat aturan yang lebih 
Su'aidi, et al/Jurnal Ekonomi Syariah Teori dan Terapan Vol. 6 No. 11 November 2019: 2361-2368; PROBLEMATIKA PENGAWASAN DEWAN PENGAWAS SYARIAH PADA BMT ALMAUN BERKAH MADANI DAN BMT MANDIRI UKHUWAH PERSADA

rinci dan jelas tentang pengawasan syariah dengan tujuan melakukan evaluasi dan menjaga konsistensi pengawasan.

\section{DAFTAR PUSTAKA}

Fatharib, Husnul. 2017. Revitalisasi peran dan Fungsi Dewan Pengawas di Lembaga Keuangan Syari'ah Kota Metro. Jurnal el-Hekam. Volume 2, Nomor 1, Juni 2017

Hamza, Hicem. 2013.Sharia Governance in Islamic Banks: effectiveness and supervision model. International Journal of Islamic and Middle Eastern Finance and Management. volume 6, Nomor 3, 2013.

Huda, Nurul, M. H. 2010. Lembaga Kevangan Islam Tinjauan Teoritis Dan Paktis. Jakarta: Prenanda Media Grup

Komite Nasional Kebijakan Corporate Governance. 2004. Pedoman Good Corporate Governance Perbankan Indonesia.

Kusuma, Laksana Candra. 2017. Peran Dewan Pengawas Syariah Pada BMT Syamil. Salatiga: IAIN Salatiga. Kuswanto, Eko. 2018. Implementasi Keputusan DSN MUI Nomor 3 Tahun 2000 Tentang Tugas dan Fungsi Dewan Pengawas Syari'ah di Bank Pembiayaan Rakyat Syariah (BPRS) Khasanah Ummat dan Bank Pembiayaan Rakyat Syariah (BPRS) Bina Amanah Satria (BAS) Purwokert. Purwokerto : Institut Agama Islam Negeri (IAIN) Purwokerto.

Moleong, J.Lexy. 2007. Metodologi Penelitan Kualitatif. Bandung: Remaja Karya

Peraturan Menteri Negara Koperasi Dan Usaha Kecil Dan Menengah Republik Indonesia Nomor: 35/PER/M.KUKM/X/2007 Tentang Pedoman Standar Operasional Manajemen Koperasi Jasa Keuangan Syariah Dan Unit Jasa Kevangan Syariah Koperasi.

Prastiwi, lin Emy. 2028. Pengaruh Independensi Dewan Pengawas Syariah Dalam Mewujudkan Good Corporate Governance Untuk Meningkatkan Kinerja

Sunandar Heri. 2005. Peran dan Fungsi Dewan Pengawas (Syariah Shari'a Supervisory Board) dalam Perbankan Syariah di Indonesia. Jurnal Hukum Islam, Volume IV, Nomor 2, Desember 2005 www.dsnmui.com, diakses pada 5 Juni 2019 